\title{
BODY DISSATISFACTION DAN PERILAKU DIET PADA REMAJA PEREMPUAN
}

\section{Body Dissatisfaction and Diet Behavior of Female Adolescents}

\author{
Anisa Olfi Safitri ${ }^{1)}$, Riangga Novrianto ${ }^{2)}$, Anggia Kargenti Evanurul Marettih ${ }^{3)}$ \\ ${ }^{12) 3)}$ Fakultas Psikologi UIN Sultan Syarif Kasim Riau
}

Diterima tanggal 06 Agustus 2019/ Disetujui tanggal 05 Desember 2019

\begin{abstract}
The aim of research was to investigate the correlation of body dissatisfaction and dieting behavior in female adolescence. Participants of this research were 204 female adolescence with 15-19 years old age range that determined from purposive sampling. Participants completed adapted version of Dutch Eating Behaviour Questionnaire (DEBQ) from Van Strien et al., (1986) and Body Shape Questionnaire (BSQ34) from Cooper, Taylor, Cooper and Fairbum (1987). Pearson Product Moment analysis was conducted and indicated that hypotheses in this research was rejected, there are negative correlation between body dissatisfaction and dieting behavior with $r=-0.229$ ( $p<0.01)$. Results indicated that high body dissatisfaction in female adolescence not always related with high dieting behavior. Another findings in this research also indicated the drastic change about body image aspect has the highest correlation with dieting behavior $r=-0.224$ ( $p<0.01)$. In summary, female adolescence expected to have ideal and healthy body image and more positive orientation about their own body.
\end{abstract}

Keywords: Body dissatisfaction, dieting behavior, female adolescents.

\begin{abstract}
ABSTRAK
Penelitian ini bertujuan untuk mengetahui hubungan antara body dissatisfaction dengan perilaku diet pada remaja perempuan. Subjek dalam penelitian ini berjumlah 204 orang remaja perempuan yang berusia 1519 tahun yang ditentukan dengan teknik purposive sampling. Pengumpulan data menggunakan skala Dutch Eating Behaviour Questionnaire (DEBQ) dari Van Strien et al., (1986) dan skala Body Shape Questionnaire (BSQ-34) dari Cooper, Taylor, Cooper dan Fairbum (1987) yang diadaptasi sesuai dengan kebutuhan penelitian. Berdasarkan analisis korelasi Pearson Product Moment, hipotesis dalam penelitian ini ditolak karena ditemukan adanya hubungan negatif antara body dissatisfaction dengan perilaku diet pada remaja perempuan dengan nilai $r=-0.229(\mathrm{p}<0.01)$. Hasil penelitian ini menunjukkan bahwa tingginya body dissatisfaction pada remaja perempuan tidak selalu diiringi dengan tingginya perilaku diet. Temuan lainnya dari penelitian ini juga menunjukkan aspek perubahan yang drastis terhadap persepsi mengenai tubuh merupakan aspek yang memiliki nilai korelasi tertinggi terhadap perilaku diet $r=-0.224$ ( $\mathrm{p}<0.01)$. Sehingga, remaja perempuan diharapkan memiliki pengetahuan tentang gambaran tubuh ideal dan sehat serta memiliki orientasi yang lebih positif terhadap tubuh yang dimiliki.
\end{abstract}

Kata kunci: Body dissatisfaction, perilaku diet, remaja perempuan.

\section{PENDAHULUAN}

Masa remaja merupakan salah satu fase perkembangan terpenting yang ditandai dengan perannya sebagai periode peralihan dan perubahan. Pada masa remaja, seseorang akan banyak mengalami perubahan, baik secara fisik maupun psikis.

\footnotetext{
*Korespondensi

Penulis:

${ }^{1)}$ olfisafitri@gmail.com

${ }^{2)}$ riangganovrianto@gmail.com
}

Terkait dengan perubahan fisik yang terjadi pada remaja, Havighurst (dalam Sarwono, 2006) menjelaskan bahwa adapun tugas-tugas perkembangan remaja, salah satu diantaranya adalah remaja mampu menerima keadaan fisiknya dan memanfaatkan keadaan tubuhnya secara efektif. Pada masa perkembangan tersebut, perubahan tubuh remaja seringkali memunculkan permasalahan tersendiri, 
sehingga remaja tidak mampu menerima keadaan fisiknya dan memanfaat tubuhnya dengan efektif. Salah satu permasalahan utama yang dihadapi oleh remaja, khususnya remaja perempuan, adalah permasalahan berat badan yang akan memberi perubahan pada bentuk tubuh sehingga menimbulkan respon berupa tingkah laku untuk memperhatikan perubahan bentuk tubuh agar terlihat ideal.

Menurut Santrock (2007), masa remaja dimulai sekitar usia 10 hingga 13 tahun dan berakhir pada usia 18 hingga 22 tahun, dimana pada usia ini remaja memiliki perhatian yang cukup kuat terhadap tubuhnya. Perhatian pada tubuh membuat remaja ingin mengubah tampilan agar terlihat ideal. Hal ini sesuai dengan penjelasan Conger dan Peterson (dalam Sarafino, 1998) bahwa pada masa remaja, para remaja biasanya mulai menyibukkan diri dengan penampilan fisik mereka dan ingin mengubah penampilan mereka. Salah satu hal yang dilakukan remaja untuk merubah tampilan adalah dengan melakukan diet.

Diet merupakan sebuah usaha untuk mengurangi atau mengontrol asupan makanan yang bertujuan untuk mengurangi atau mempertahankan berat badan sesuai dengan keinginan individu (Hawks, Hala, Terisue \& Natalie, 2008). Polivy dan Herman (1987) menjelaskan perilaku diet adalah usaha individu untuk menurunkan berat badan yang dapat dilakukan dengan berbagai cara namun tetap berfokus pada pengaturan pola makan oleh pelaku diet.

$$
\text { Sztainer dan Peter (2000) }
$$

melakukan penelitian pada 6728 remaja tingkat 5 sampai 12, mereka menemukan bahwa perempuan lebih sering memperhatikan berat badan dibandingkan pria, hampir setengah dari remaja perempuan $(45,4 \%)$ melaporkan bahwa remaja perempuan telah melakukan diet dengan beberapa alasan, alasan terbesar adalah agar terlihat lebih baik. Penelitian tersebut menunjukkan bahwa remaja perempuan sebanyak $88,5 \%$ melakukan diet agar terlihat lebih baik dibandingkan remaja laki-laki (62,2\%). Artinya remaja perempuan lebih banyak melakukan diet agar penampilan terlihat bagus, cantik dan sesuai dengan bentuk tubuh ideal seperti yang diinginkan.

Beberapa remaja perempuan melakukan diet karena memperhatikan kesehatan, namun Sarafino (1998) menyatakan bahwa ada juga beberapa orang yang termotivasi oleh bagaimana mereka terlihat dan apa yang orang lain pikirkan. Begitupun remaja perempuan melakukan diet agar terlihat ideal dan diterima masyarakat dan terkadang remaja perempuan melakukan kesalahan ketika berdiet.

Salah satu diet yang membahayakan kesehatan adalah diet ketat seperti makan hanya sekali sehari tanpa berkonsultasi dengan dokter atau ahli gizi, remaja perempuan hanya memikirkan bagaimana menjadi kurus dengan cepat dan mudah tanpa melihat akibat yang akan ditimbulkan oleh diet yang dilakukan. Berdasarkan hasil survei yang dilakukan oleh para ahli gizi di kawasan DIY menyebutkan, $37 \%$ remaja perempuan yang melakukan diet mengalami anemia (Republika.co.id, 2013). Diet super ketat yang dilakukan oleh remaja akan berdampak pada hilangnya perasaan lapar sehingga pada akhirnya akan memunculkan gangguan makan seperti bulimia dan anoreksia (Setiawan, 2013).

Gangguan makan bulimia dan anoreksia akibat diet yang dilakukan sangat berbahaya, para penderita bulimia dan anoreksia akan memiliki harga diri rendah, gangguan terhadap skema tubuh, dan akan mengalami depresi. Selain itu, penelitian yang dilakukan Hill, Rogers dan Blundell (Hill dan Sarah, 1992) juga menemukan bahwa seorang remaja yang berdiet kemudian menghentikan dietnya dapat menjadi perilaku makan berlebihan pada tahun-tahun berikutnya. Berdasarkan penelitian tersebut dapat menjadi bukti bahwa perilaku diet dapat membawa dampak buruk bagi kesehatan remaja.

Banyak faktor yang berhubungan dengan alasan remaja perempuan melakukan diet. Faktor individu, keluarga dan lingkungan berperan terhadap perilaku diet pada remaja, namun ketidakpuasan pada bentuk tubuh dan motivasi menjadi lebih kurus merupakan faktor terbesar 
(Findlay, 2004). Perubahan fisik yang terjadi pada remaja perempuan berupa peningkatan lemak tubuh menyebabkan ketidakpuasan remaja perempuan pada tubuhnya, sehingga remaja perempuan berusaha menurunkan berat badannya dengan melakukan diet (Abdurrahman, 2014)

Ketidakpuasan pada bentuk tubuh atau body dissatisfaction merupakan bagian dari Body Image. Grogan (2007) mendefinisikan body dissatisfaction sebagai pikiran dan perasaan negatif individu terhadap tubuhnya. Cooper, dan Fairbum (dalam Pietro \& Silveira, 2009) menjelaskan bahwa body dissatisfaction adalah penilaian individu ketika membandingkan persepsi citra tubuh dengan orang lain, orientasi berlebihan terhadap citra tubuh, persepsi diri sendiri terhadap tubuh dan adanya perubahan yang drastis terhadap tubuh.

Penelitian ini bertujuan untuk mengetahui hubungan antara body dissatisfaction dan perilaku diet pada remaja perempuan. Hasil penelitian ini diharapkan dapat memperkaya khazanah ilmu pengetahuan psikologi khususnya di bidang psikologi perkembangan dan psikologi klinis serta menjadi referensi tambahan mengenai faktor-faktor yang mempengaruhi perilaku diet pada remaja perempuan. Hipotesis yang diajukan dalam penelitian ini adalah terdapat hubungan positif antara body dissatisfaction dan perilaku diet pada remaja perempuan.

\section{METODE PENELITIAN}

\section{Sampel}

Sampel dalam penelitian ini diambil dengan menggunakan teknik purposive sampling. Sampel yang digunakan dalam penelitian ini berjumlah 204 remaja perempuan yang melakukan diet, berusia 15-19 tahun yang masih berstatus siswa dan berdomisili di kota Pekanbaru.

\section{Pengukuran}

Perilaku diet dalam penelitian ini diukur dengan mengadopsi skala Dutch Eating Behaviour Questionnaire (DEBQ) dari Van Strien et al., (1986). Dutch Eating Behaviour Questionnaire (DEBQ) terdiri dari 33 pertanyaan mengenai perilaku diet dan telah diterjemahkan oleh peneliti ke dalam bahasa Indonesia. Alat ukur DEBQ dimodifikasi dalam bentuk pernyataan dengan 5 alternatif jawaban.

Body dissatisfaction di dalam penelitian ini ini diukur dengan mengadaptasi body shape questionnaire (BSQ-34) dari Cooper, Taylor, Cooper, dan Fairbum (1987) untuk mengukur kepedulian terhadap bentuk tubuh. Pook, Tuschen \& Brahler (2008) menyatakan Body shape questionnaire (BSQ-34) adalah skala yang sudah diakui secara luas untuk mengukur body dissatisfaction

\section{HASIL DAN PEMBAHASAN}

\section{Hasil}

Berdasarkan hasil uji korelasi Pearson Product Moment pada variabel body dissatisfaction dan perilaku diet diperoleh koefisien korelasi sebesar -0,229 $(p<0.01)$. Mengacu pada ketentuan penerimaan atau penolakan hipotesis sebagaimana yang telah dikemukakan sebelumnya, maka hipotesis yang diajukan di dalam penelitian ini ditolak. Berdasarkan hasil analisis terdapat hubungan negatif antara body dissatisfaction dan perilaku diet.

Koefisien determinasi ( $R$ square) variabel body dissatisfaction terhadap perilaku diet adalah sebesar 0.053 atau sebesar 5.3\%. Sumbangan efektif masingmasing aspek body dissatisfaction terhadap perilaku diet dapat dilihat pada tabel 1 . 
Versi Online: http://journal.ubm.ac.id/index.php/psibernetika DOI: http://dx.doi.org/10.30813/psibernetika.v12i2.1673 Hasil Penelitian

Tabel 1. Sumbangan efektif masing-masing aspek body dissatisfaction

\begin{tabular}{lc}
\hline $\begin{array}{l}\text { Aspek Body } \\
\text { Dissatisfaction }\end{array}$ & $\begin{array}{l}\text { Sumbangan } \\
\text { Efektif (\%) }\end{array}$ \\
\hline $\begin{array}{l}\text { Persepsi diri } \\
\text { terhadap bentuk } \\
\text { tubuh }\end{array}$ & $2.43 \%$ \\
Membandingkan \\
persepsi mengenai \\
citra tubuh dengan \\
orang lain \\
$\begin{array}{l}\text { Sikap yang fokus } \\
\text { terhadap citra tubuh }\end{array}$ \\
$\begin{array}{l}\text { Perubahan yang } \\
\text { drastis terhadap } \\
\text { persepsi mengenai } \\
\text { tubuh }\end{array}$ \\
Jumlah
\end{tabular}

Berdasarkan tabel 1 dapat diketahui bahwa aspek dari body dissatisfaction yang memberikan sumbangan efektif paling besar terhadap variabel perilaku diet adalah perubahan yang dratis terhadap persepsi mengenai bentuk tubuh dengan persentase sebesar $2.73 \%$.

\section{Pembahasan}

Penelitian ini dilakukan dengan tujuan untuk mengetahui hubungan antara body dissatisfaction dengan perilaku diet pada remaja perempuan. Hipotesis yang diajukan adalah hipotesis yang memiliki arah positif dengan asumsi awal terdapat hubungan positif antara body dissatisfaction dan perilaku diet pada remaja perempuan.

Namun berdasarkan hasil analisis data yang dilakukan, diperoleh koefisien korelasi $(\mathrm{r})=-0.229(p<0.01)$. Hal ini menunjukkan bahwa terdapat korelasi negatif yang signifikan antara body dissatisfaction dan perilaku diet pada remaja perempuan. Artinya, ketidakpuasan remaja perempuan terhadap bentuk tubuhnya tidak selalu diiringi dengan tingginya perilaku diet yang dilakukan.

Hasil tersebut juga didukung oleh nilai koefisien determinasi ( $R$ square) yang dapat diberikan variabel body dissatisfaction terhadap perilaku diet hanya sebesar $5.3 \%$, sedangkan $94.7 \%$ lainnya ditentukan oleh faktor-faktor lain yang
Jurnal Psibernetika Vol.12 (2): 100-105. Oktober 2019 p-ISSN: 1979-3707 e-ISSN: 2581-0871

dapat menjadi pemicu munculnya perilaku diet. Faktor-faktor tersebut antara lain adalah nilai kesehatan (health belief), kepribadian, pengaruh hubungan keluarga, dan status sosial ekonomi keluarga. Oleh sebab itu, body dissatisfaction bukanlah faktor tunggal penyebab individu untuk melakukan diet.

Penelitian yang dilakukan oleh Hill dan Sarah (1992) menemukan bahwa remaja perempuan termotivasi untuk melakukan diet karena merasa tidak puas dengan bentuk dan ukuran tubuhnya. Berbeda dengan temuan peneliti yang menunjukkan bahwa body dissatisfaction bukanlah prediktor perilaku diet yang dilakukan oleh remaja perempuan.

Remaja yang puas dengan bentuk tubuh akan semakin mengontrol berat badannya, hal ini karena semakin puas remaja perempuan dengan tubuhnya maka akan semakin mempertahankan berat badan dan bentuk tubuh yang dimiliki dengan cara diet. Hal ini sesuai dengan faktor yang menyebabkankan body dissatisfaction menurut Brehm (dalam Asri \& Setiasih, 2004) yaitu kebutuhan atas kendali membuat beberapa orang merasa nyaman apabila dapat mengontrol makanan dan berat badannya. Mampu mengontrol tubuh sendiri dapat membantu seseorang merasa bahwa paling tidak mereka memiliki kendali atas kehidupannya. Salah satu cara individu untuk mengontrol asupan makanan yang akan dikonsumsi adalah dengan melakukan diet, diet yang dilakukan bertujuan untuk mengurangi, mengontrol, dan mempertahankan berat badan.

Prima dan Endah

mengemukakan bahwa remaja perempuan melakukan diet agar dapat meningkatkan rasa percaya diri ketika sedang bersosialisasi dengan lingkungan sekitar. Dengan menjaga berat badan dan bentuk tubuh maka akan mempengaruhi penampilan serta dapat meningkatkan rasa percaya diri remaja perempuan ketika sedang bersosialisasi dengan lingkungan sekitarnya.

Namun demikian, penampilan tidak selalu menjadi satu-satunya alasan seseorang merasa diterima di lingkungan sosialnya. Ada banyak faktor yang dapat 
membuat remaja perempuan mampu bersosialisasi dengan baik dengan lingkungannya, seperti memiliki kepribadian yang menyenangkan, memiliki prestasi serta memiliki tingkah laku dan kebiasaan baik (Prima \& Endah, 2013). Dengan kata lain, untuk memperoleh penerimaan di lingkungan sosial tidak serta merta mengharuskan remaja perempuan untuk melakukan diet untuk mengubah penampilan, tetapi yang menjadi penting adalah bagaimana remaja perempuan mampu untuk bersosialisasi dengan lingkungannya.

Perubahan drastis terhadap persepsi mengenai bentuk tubuh merupakan aspek dari body dissatisfaction yang memiliki kontribusi paling tinggi terhadap perilaku diet remaja perempuan yaitu sebesar 2.73 $\%$. Perubahan persepsi atau penilaian mengenai bentuk tubuh terjadi karena informasi yang didapat tentang bentuk tubuh ideal tidak sesuai dengan bentuk tubuh yang dimiliki saat ini. Ketika terjadi perubahan penilaian pada remaja perempuan tentang seluruh maupun sebagian dari bentuk tubuh yang mereka miliki, maka mereka akan berpikir bahwa bentuk tubuh mereka tidak lagi sesuai dengan bentuk tubuh yang diinginkan, namun demikian mereka tidak melakukan tindakan agar tubuhnya sesuai dengan bentuk tubuh yang diinginkan dengan melakukan diet.

Sebanyak $131 \quad(64.2 \%)$ subjek penelitian memiliki indeks massa tubuh (IMT) dengan kategori normal, sedangkan 42 (20.6\%) subjek penelitian lainnya memiliki IMT yang cukup tinggi. Hal ini menunjukkan bahwa sebagian besar remaja perempuan melakukan diet meskipun memiliki berat badan yang normal. Uroniu, Putnoky, dan Vlaicu (2011) menjelaskan bahwa beberapa remaja perempuan memiliki persepsi yang salah terhadap berat badannya, remaja yang memiliki berat badan normal menganggap bahwa berat badan mereka berlebih (overweight) dan mereka berusaha untuk menurunkan berat badannya.

Temuan korelasi negatif antara body dissatisfaction dan perilaku diet pada remaja perempuan mengindikasikan bahwa remaja perempuan yang merasa tidak puas dengan bentuk tubuhnya cenderung acuh dan tidak memiliki keinginan untuk memperbaiki bentuk tubuhnya dengan cara melakukan diet. Namun, di sisi lain remaja perempuan yang merasa puas dengan bentuk tubuhnya akan cenderung berusaha mempertahankan dan mengontrol bentuk tubuhnya agar tetap ideal.

\section{SIMPULAN}

Berdasarkan hasil penelitian maka dapat disimpulkan bahwa terdapat hubungan negatif antara body dissatisfaction dan perilaku diet pada remaja perempuan. Artinya, ketidakpuasan remaja perempuan terhadap bentuk tubuhnya tidak selalu diiringi dengan tingginya perilaku diet yang dilakukan. Sebaliknya, di sisi lain remaja perempuan yang merasa puas dengan bentuk tubuhnya akan cenderung berusaha mempertahankan bentuk tubuhnya agar tetap ideal dengan cara melakukan diet.

\section{DAFTAR PUSTAKA}

Abdurrahman, F. (2014). Faktor-faktor pendorong perilaku diet tidak sehat pada wanita usia dewasa awal studi kasus pada mahasiswa Universitas Mulawarman. eJournal Psikologi, 2(2), 163-170.

Asri, D., \& Setiasih. (2004). Penerapan metode akupunktur pada wanita peyandang obesitas. Anima Indonesian Psychological Journal, 9(3), 286-289.

Cooper, P. J., Taylor, M. J., Cooper, Z., \& Fairbum, C. G. (1987). the development and validation of the body shape questionnaire. International Journal of Eating Disorders, 6(4), 485-494.

Findlay, S. M. (2004). Dieting in adolescense. Adolescent Health Committee. Paediatry Child Health, 9(7), 487-91. 
Versi Online: $h$ ttp://journal.ubm.ac.id/index.php/psibernetika DOI: http://dx.doi.org/10.30813/psibernetika.v12i2.1673 Hasil Penelitian

Grogan, S. (2007). Body image: understanding body dissatisfaction in men, women, and children ( $\left.2^{\text {nd }} e d.\right)$. NY: Psychology Press.

Hawks, S. R., Hala, M., Terisue, S. \& Natalie, D. L. C. (2008). Classroom approach for managing dietary restraint, negative eating styles, and body image concerns among college women. Journal of American College Health, 56(4), 359-366.

Hill, A. J., \& Sarah O. (1992). eating in the adult world: the rise of dieting in childhood an adolescence. British Journal of Clinical Pycbology, 31, 95-105.

Pietro, M. D., \& Silveira, D. X. D. (2009). internal validity, dimensionality and performance of the body shape questionnaire in a group of Brazillian college students. Rev Bras Psiquatr, 31(1), 21-4.

Pook, M., Tuschen-Caffier, B., \& Brahler, E. (2008). evaluation and comparison of different versions of the body shape questionnaire. Psychiatry Research, 158, 67-73.

Polivy, J \& Herman C. P. (1987). Diagnosis and treatment of normal eating. Journal of Consulting and Clinical Psychology, 55(5), 635-644.

Prima, E. \& Endah, P. (2013). Hubungan antara body dissactisfaction dengan kecenderungan perilaku diet pada remaja putri. Jurnal Psikologi Integratif, 1(1), $17-30$.

Santrock, J. W., (2003). Adolescents (perkembangan remaja) Alih Bahasa: Benedictine Widyasinta. Jakarta: Erlangga

Sarafino, E. P. (1998). Health psychology: biopsychological interaction third edition. New York: John Wiley \& Sons, Inc.

Setiawan, A. (2013). diet ketat akibatkan gangguan makan. http://www.dw.de/diet-ketatakibatkan-gangguan-makan/a16723075. Tanggal akses: 7 Mei 2017.

Sztainer, D. N., \& Peter, J. H. (2000). weight-related behaviours among
Jurnal Psibernetika Vol.12 (2): 100-105. Oktober 2019 p-ISSN: 1979-3707 e-ISSN: 2581-0871

adolescent girls and boys. Artikel. Arch Pediatr Adolesc Med, 154.

Van Strien, T., Frijters, J. E., Bergers, G. P., \& Defares, P. B. (1986). The Dutch Eating Behavior Questionnaire (DEBQ) for assessment of restrained, emotional, and external eating behavior. International Journal of Eating Disorder, 5(2), 295-315. 